\title{
A randomized comparative evaluation of local infiltration analgesia, extended nerve blocks, and conventional analgesia in pain management after total knee arthroplasty
}

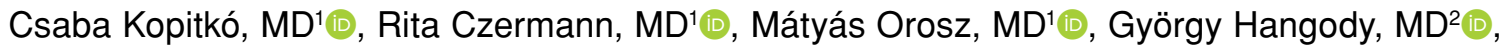

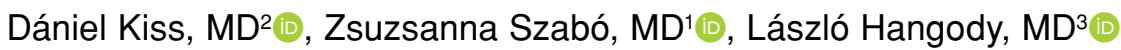 \\ ${ }^{1}$ Department of Anesthesiology and Intensive Therapy, Uzsoki Str. Teaching Hospital, Budapest, Hungary \\ ${ }^{2}$ Department of Orthopedics and Traumatology, Uzsoki Str. Teaching Hospital, Budapest, Hungary \\ ${ }^{3}$ Department of Traumatology, Semmelweis University, Budapest, Hungary
}

The main goals after total knee arthroplasty (TKA) are to reduce the postoperative pain, to diminish the transfusion need, and to ensure the ability for early ambulation. ${ }^{[1]}$ Local infiltration anesthesia (LIA) is an easy and uprising method to achieve these extremely complex goals. ${ }^{[2,3]}$ The optimal volume and composition of the mixture are still unclear. Analgetic issues provided by anesthetists tend to move from neuraxial toward peripheral (mainly femoral nerve's) blockades, leaving the pain emerging from posterior and medial structures of the joint untreated. ${ }^{[3-10]}$ To the best of our knowledge, there are only few studies using blockade of all the three nerves, where posterior approach was used to perform sciatic block..$^{[1,12]}$

Received: March 12, 2021

Accepted: May 06, 2021

Published online: June 11, 2021

Correspondence: Csaba Kopitkó, MD. Department of Anesthesiology and Intensive Therapy, Uzsoki Str. Teaching Hospital, 1145 Budapest, Hungary.

E-mail: kopcsab2@gmail.com

Doi: $10.52312 /$ jdrs.2021.68

Citation: Kopitkó C, Czermann R, Orosz M, Hangody G, Kiss D, Szabó $Z$, et al. A randomized comparative evaluation of local infiltration analgesia, extended nerve blocks, and conventional analgesia in pain management after total knee arthroplasty. Jt Dis Relat Surg 2021;32(2):290-298.

(C2021 All right reserved by the Turkish Joint Diseases Foundation

This is an open access article under the terms of the Creative Commons Attribution-NonCommercial License, which permits use, distribution and reproduction in any medium, provided the original work is properly cited and is not used for commercial purposes (http://creativecommons.org/licenses/by-nc/4.0/).

\section{ABSTRACT}

Objectives: The aim of this study was to analyze the postoperative effects of extended nerve blocks and local infiltration analgesia (LIA) on postoperative pain control, muscle weakness, and blood loss after total knee arthroplasty (TKA).

Patients and methods: Between February $24^{\text {th }} 2020$ and July $10^{\text {th }} 2020$, a total of 161 patients (55 males, 106 females; median age: 69.0 years [IQR 63.0-75.0], range, 41 to 81 years) who underwent primary TKA were randomly allocated into three parallel groups according to their concomitant procedure in a double-blind fashion: (i) those to whom nerve blockade was performed after competition of surgery under the duration of spinal anesthesia $(\mathrm{n}=50)$; (ii) those to whom LIA was performed during surgery $(\mathrm{n}=52)$, and (iii) control group $(\mathrm{n}=59)$. The content of LIA was $10-10 \mathrm{~mL}$ of $20 \mathrm{mg}$ lidocaine with $0.01 \mathrm{mg}$ adrenalin and $100 \mathrm{mg}$ ropivacaine, $1 \mathrm{~mL}(30 \mathrm{mg})$ ketorolac, and $5 \mathrm{~mL}(500 \mathrm{mg})$ tranexamic acid was diluted by $50 \mathrm{~mL} 0.9 \% \mathrm{NaCl}$ under aseptic conditions. Outcome parameters were the evaluation of pain until the evening of first postoperative day (24 to $36 \mathrm{~h}$ ), mobilization, and blood loss within the first three postoperative days.

Results: The pain was maximal between 4 and $8 \mathrm{~h}$ postoperatively, when the effect of the spinal anesthetic drugs disappeared. During this critical period, tolerable pain (Numerical Rating Scale, NRS $\leq 3$ ) was observed in $52 \%, 42 \%$, and $19 \%$ of nerve blockade in LIA and control groups, respectively. None of the patients complained of high-intensity pain $($ NRS $>8$ ) in the LIA group, which was a significant difference from the block and control groups (10\% and $14 \%, \mathrm{p}<0.008$, respectively). There was no significant muscle weakness associated with the use of this extended block. The decrease in hemoglobin level was significantly lower in the LIA group than in the control and block groups (odds ratio [OR]: $0.379,95 \%$ confidence interval $[\mathrm{CI}]: 0.165-0.874$ for nerve blockade $v s$. LIA, OR: $1.189,95 \%$ CI: $0.491-2.880$ for nerve blockade vs. control, OR: $0.319,95 \%$ CI: $0.140-0.727$, respectively). The common language effect size for pain in each referred interval in each group and for decrease of hemoglobin between the first and third postoperative days fell between 0.507 and 0.680 .

Conclusion: This study demonstrates that LIA technique offers a fast and safe treatment option for pain relief after TKA. No clinically relevant muscle weakness was observed among groups according to field block applications. Significant advantages were also achieved in blood loss.

Keywords: Local infiltration analgesia, nerve block, postoperative pain, total knee arthroplasty. 
More than 1,500 primary TKAs are performed annually in our institution, which is a regional orthopedic center serving as a tertiary referral center in TKA. Postoperative analgesia is primarily based on systemic analgesics and administered by nurses according to medical instructions and protocols tailored to the severity of the pain. In recent years, other methods have been used including peripheral nerve blocks performed by the anesthesiologist, and infiltration of the surgical area by the orthopedic surgeon during the operation.

In this study, we aimed to investigate the analgetic effects of small volume LIA containing tranexamic acid and extended (femoral, obturator and sciatic) single shot nerve blockades.

\section{PATIENTS AND METHODS}

This double-blind, prospective, randomizedcontrolled study was conducted at the Orthopedics and Traumatology Department of Uzsoki Hospital, Budapest, Hungary between February $24^{\text {th }}, 2020$ and July $10^{\text {th }}, 2020$. Prior to study, a written informed consent was obtained from each participant. The study protocol was approved by the local Ethics Committee (No: 127-IK/2020). The study was conducted in accordance with the principles of the Declaration of Helsinki.

A total of 161 patients (55 males, 106 females; median age: 69.0 years [IQR 63.0-75.0], range, 41 to 81 years) who underwent elective primary TKA were included in the study. Exclusion criteria included allergies against local anesthetics or other components of LIA, dementia, neuropathic diseases, local skin infections, or patients who did not give consent to participate in the study. The patients were randomly assigned to one of three parallel groups, initially at 1:1:1 ratio by an independent investigator: (i) those to whom nerve blockade was performed after competition of surgery under the duration of spinal anesthesia; (ii) those to whom LIA was performed during surgery, and (iii) control group (Figure 1). The patients were randomized into the same group in the same day. The groups were changed sequentially day by day according to a preliminary determined order, until the number of patients reached 50 in the smallest group. The participant, the surgeon, and anesthesiologist became aware of the decision immediately before surgery. All patients received midazolam for decreasing the psychical stress in the operating room, resulting in amnesia for the interventions. The same dressing was provided to all patients to ensure double blinding on the ward after surgery. $1 \mathrm{~g}$ tranexamic acid was administered intravenously to all patients in the operating theater prior to surgery.

Totally bupivacaine $0.5 \%$ was employed for intrathecal anesthesia in an appropriate dose according to the decision of anesthesiologist, who was trained

\begin{tabular}{|c|c|c|c|c|c|}
\hline & & & \multicolumn{2}{|c|}{$\begin{array}{l}\text { Excluded }(n=58) \\
\text { - Not meeting inclusion criteria }(n=19) \\
\text { - Declined to participate }(n=31) \\
\text { - Other reasons }(n=8)\end{array}$} & \\
\hline & & Randomized $(n=161)$ & & & \\
\hline$\downarrow$ & Allocation & $\nabla$ & Allocation & \multicolumn{2}{|r|}{$\nabla$} \\
\hline $\begin{array}{l}\text { Allocated to nerve blockade }(n=59) \\
\text { - Received allocated intervention }(n=59) \\
\text { - Did not receive allocated intervention } \\
\text { (give reasons) }(n=0)\end{array}$ & & $\begin{array}{l}\text { Allocated to LIA }(n=52) \\
\text { - Received allocated intervention }(n=52) \\
\text { - Did not receive allocated intervention } \\
\text { (give reasons) }(n=0)\end{array}$ & & \multicolumn{2}{|c|}{$\begin{array}{l}\text { Allocated to control group }(n=50) \\
\text { - Received allocated intervention }(n=50) \\
\text { - Did not receive allocated intervention } \\
\text { (give reasons) }(n=0)\end{array}$} \\
\hline$\downarrow$ & Follow-up & $\nabla$ & Follow-up & & $\downarrow$ \\
\hline Lost to follow-up (give reasons) $(n=33)$ & & Lost to follow-up (give reasons) $(n=21$ ) & & \multicolumn{2}{|c|}{ Lost to follow-up (give reasons) $(n=13)$} \\
\hline$\downarrow$ & Analysis & $\downarrow$ & Analysis & & $\nabla$ \\
\hline $\begin{array}{l}\text { Analyzed ( } n=50 \text {; in } 24-36 \text { hours period } n=26 \text { ) } \\
\text { - Excluded from analysis }(n=0)\end{array}$ & & $\begin{array}{l}\text { Analyzed }(n=52 ; \text { in } 24-36 \text { hours period } n=31) \\
\text { - Excluded from analysis }(n=0)\end{array}$ & & $\begin{array}{l}\text { Analyzed }(n=59 \\
\text { - Excluded fr }\end{array}$ & $\begin{array}{l}\text { 4- } 36 \text { hours period } n=37 \text { ) } \\
\text { nalysis }(n=0)\end{array}$ \\
\hline
\end{tabular}


and experienced in orthopedic anesthesia. General anesthesia was chosen in one, five, and three patients in the nerve blockade, LIA and control groups, respectively. The postoperative evaluation was done also by independent investigators. Investigators who performed randomization and evaluated patients on the ward after surgery were different from each other and from those who performed the interventions. No interim analyses for efficacy or futility were done. The number of arthroplasties carried out by the same surgeon was comparable among the groups. Operative technique was the same in all three groups -midline skin incision, mini-midvastus approach, implantation of Sanat Swing cemented total knee prostheses. ${ }^{[13]}$ Individuals who were participants in other clinical studies were excluded.

\section{Performing the nerve blocks}

The sensory innervation of knee joint was supplied by the femoral (anterior part), obturator (medial part), and sciatic (posterior part) nerves (Figure 2). Each nerve was targeted in the same patient aiming as complete postoperative analgesia as it was possible. A total dose of $40 \mathrm{~mL} 0.25 \%(2.5 \mathrm{mg} / \mathrm{mL})$ of bupivacaine was administered, which is below the toxic level in a patient of $70 \mathrm{~kg}$. The ultrasound-guided blockades (SonoScape X3, 2-6.8 MHz convex transducer) of these nerves were performed in supine position as follows:

Femoral nerve: After standard preparation of skin, the femoral artery was identified at or slightly below the level of femoral crease. The femoral nerve was ascertained lateral from the femoral artery under the fascia iliaca. The needle of $100 \mathrm{~mm}$ was inserted in-plane underneath the fascia near to the nerve. The passage through the fascia was ensured by feeling a pop and by visualization of the spread of 1 to $2 \mathrm{~mL}$ of $0.25 \%$ of bupivacaine. A field block was applied by $15 \mathrm{~mL}$ of local anesthetic without any verifications by nerve stimulation. Careful and repeated aspirations were carried out prior and during the injection to avoid the inadvertent intravascular administration.

Obturator nerve: After blockade of femoral nerve, the transducer was moved medially at the same level and the pectineus, the adductor longus and the adductor brevis muscles were identified. Both the anterior (mostly sensory) and the posterior (mostly motor) branches of obturator nerve are located in the fascial boundary of adductor brevis muscle. The tip of needle was advanced from lateral under the plane of anterior fascia of adductor brevis muscle. The position was verified by feeling the loss of resistance and the spread of local anesthetic. A total amount of
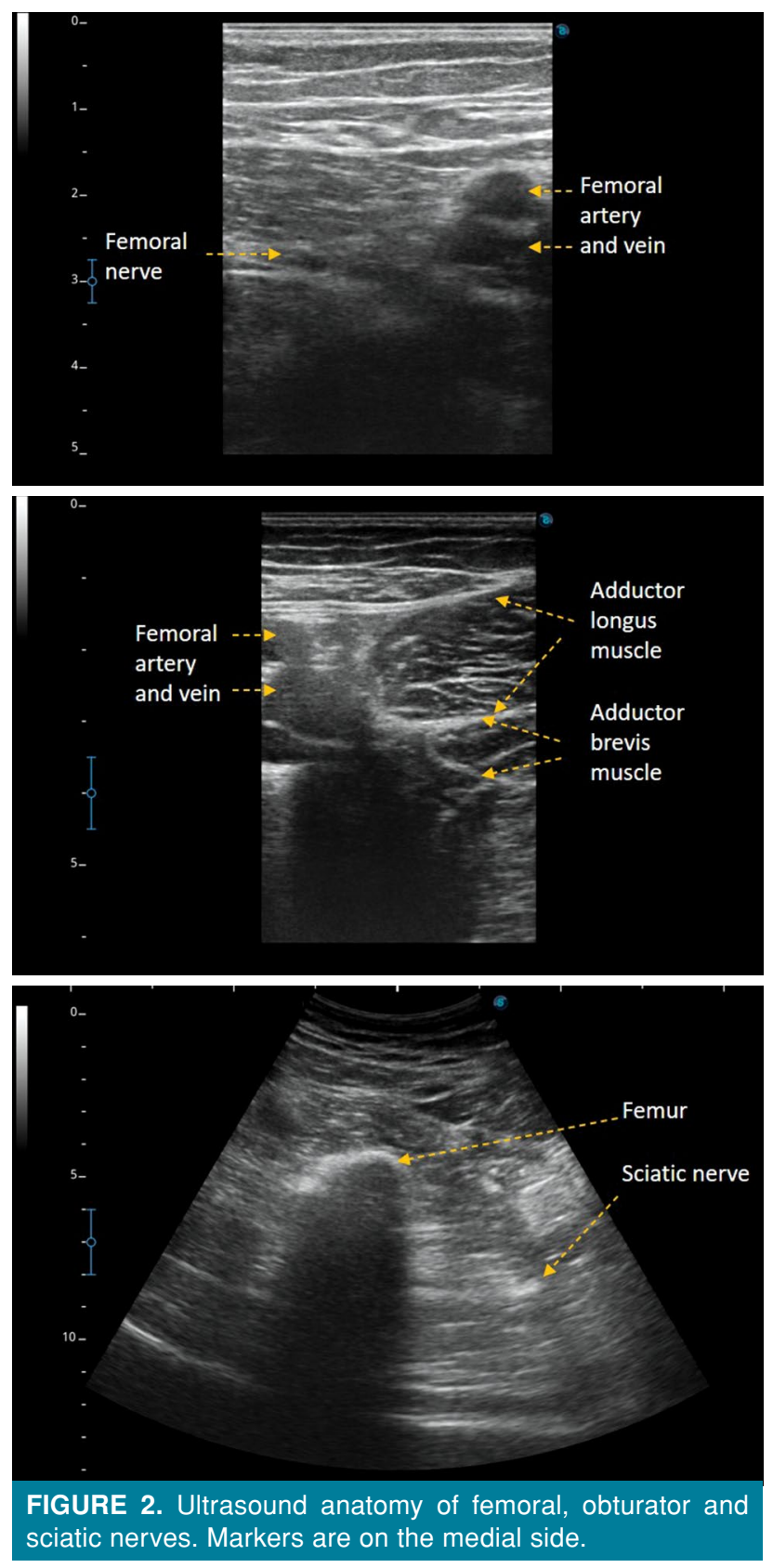

$5 \mathrm{~mL}$ was injected after careful aspiration. The needle was inserted to superficial from the deeper fascia of adductor brevis muscle. The careful aspiration and the injection of $5 \mathrm{~mL}$ of $0.25 \%$ of bupivacaine was repeated.

Sciatic nerve: The anterior approach was selected. The femur was identified according to its intensive echogenic cap and the corresponding shadow behind it. The sciatic nerve is located medially from the bone under the fascia of adductor magnus muscle. The needle was conducted in-plane, the passage through 
the fascia was confirmed by experiencing the pop. Totally $15 \mathrm{~mL}$ of $0.25 \%$ bupivacaine was injected after careful and repeated aspirations.

\section{Performing LIA}

Local infiltration analgesia was carried out by the operating orthopedic surgeon. Totally 10-10 mL of short- and long-acting local anesthetics $(20 \mathrm{mg}$ lidocaine, $0.01 \mathrm{mg}$ adrenalin; $100 \mathrm{mg}$ ropivacaine), $1 \mathrm{~mL}$ $(30 \mathrm{mg})$ ketorolac and $5 \mathrm{~mL}(500 \mathrm{mg})$ tranexamic acid were diluted by $50 \mathrm{~mL} 0.9 \%$ sodium chloride $(\mathrm{NaCl})$ under aseptic conditions. After proper resection of patella, tibial, and femoral surfaces approximately half of this solution were infiltrated to the posterior and lateral capsule structures and around collateral ligaments, while the tourniquet was still inflated. After this infiltration tourniquet was released, an adequate hemostasis was achieved, and cementation of implant components were performed. After wound closure, the remaining amount of mixture was injected into the skin and the subcutaneous tissue around the approach.

All patients received the standard postoperative analgetic regime. The postoperative pain was controlled by administration of scheduled oral non-steroid anti-inflammatory drugs (NSAIDs) and low-dose $(25 \mathrm{mg})$ tramadol on time-contingent, around-the-clock basis. The pain was checked regularly, and tailored analgesics were administered as needed according to the decision of the physician, who was blinded to the study interventions. The data were collected separately in the operating theatre and on the ward aiming to ensure the double-blind manner, as certain as possible. Intensity of pain was expressed according to Numerical Rating Scale (NRS) from 0 to $10 .{ }^{[14]}$ The patients were asked to rate their pain verbally by an independent person (ward physician or nurse), who had no information about the type of intervention. The NRS values were registered every $4 \mathrm{~h}$ until midnight, and every 8 to $12 \mathrm{~h}$ on the first postoperative day.
Postoperative physical training was started on the first postoperative day. To assess the muscle weakness described in the literature, physical therapists recorded that whether they detected muscle weakness which hindered physiotherapy. Outcome parameters were the evaluation of pain until the evening of first postoperative day ( 24 to $36 \mathrm{~h}$ ), mobilization, and blood loss in the first three postoperative days. In the absence of contraindications, on the first postoperative day, physical therapists measured the range of articular movement in an unloaded (sitting) position, helped the patients to stand up and walk using elbow crutches or walking frame, which is a pivotal issue for rapid recovery. Second-day task was to walk short distances (10 to $30 \mathrm{~m}$ ) and, on the third postoperative day, stair climbing was instructed. If any of these tasks could not be carried out, due to muscular weakness, it was considered to be decreased muscular function.

Serum hemoglobin levels were also measured preoperatively, on the first and on the third postoperative days.

\section{Statistical analysis}

Sample size calculation was performed using an online calculator (https://clincalc.com/stats/ samplesize.aspx). Anticipating means 6 and 4 for the two groups (1:1 ratio) with 2 as standard deviation for nerve blockade group (0.05 for alpha with $80 \%$ power), the sample size was calculated as 32 (16 for each groups). ${ }^{[15]}$ A dropout rate of $10 \%$ was expected. Due to the uncertainty of efficacy of locally administered tranexamic acid, at least 50 participants were planned to be included in each group.

Statistical analysis was performed using the IBM SPSS version 23.0 software (IBM Corp., Armonk, NY, USA). Descriptive data were presented in median and interquartile range (IQR) or number and frequency, where applicable. The median values of the different groups were compared using the Mann-Whitney U test

\begin{tabular}{|c|c|c|c|c|c|c|c|c|c|c|c|c|c|c|c|}
\hline \multicolumn{16}{|c|}{$\begin{array}{l}\text { TABLE I } \\
\text { characteristics of patients }\end{array}$} \\
\hline & \multicolumn{5}{|c|}{ Nerve blockade group } & \multicolumn{5}{|c|}{ LIA group } & \multicolumn{5}{|c|}{ Control group } \\
\hline & $\mathrm{n}$ & $\mathrm{n}$ & $\%$ & Median & IQR & $\mathrm{n}$ & $\mathrm{n}$ & $\%$ & Median & IQR & $\mathrm{n}$ & $\mathrm{n}$ & $\%$ & Median & IQR \\
\hline Age (year) & 50 & & & 70.0 & $66.5-75.5$ & 52 & & & 70.0 & $63.0-75.0$ & 59 & & & 67.0 & $62.0-74.0$ \\
\hline Sex & 50 & & & & & 52 & & & & & 59 & & & & \\
\hline Male & & 18 & 32 & & & & 17 & 33 & & & & 20 & 34 & & \\
\hline Female & & 36 & 64 & & & & 35 & 67 & & & & 39 & 66 & & \\
\hline $\mathrm{BMI}\left(\mathrm{kg} / \mathrm{m}^{2}\right)$ & 50 & & & 30.6 & $27.8-34.5$ & 52 & & & 31.8 & $27.4-36.1$ & 58 & & & 32.0 & $28.5-35.2$ \\
\hline
\end{tabular}


and the occurrence rates using the chi-square test. Confidence intervals (95\%) were calculated according to the formula described by Hosmer-Lemeshow. A $p$ value of $<0.05$ was considered statistically significant.

\section{RESULTS}

There was no significant difference in the baseline demographic characteristics of the patients among the groups (Table I). No adverse reactions were observed.

The intensity of pain was maximal between 4 and $8 \mathrm{~h}$ after the competition of surgery in each group (Figure 3), when the effect of spinal anesthesia was ceased. In this period, tolerable pain (NRS $\leq 3$ ) was observed in $52 \%, 42 \%$, and $19 \%$ of nerve blockade,
LIA, and control groups, respectively (Figure 4). A high intensity of pain (NRS $>8$ ) was reported in $10 \%$ and in $14 \%$ of nerve blockade and control groups, respectively $(\mathrm{p}<0.008)$; however, it was not found in the LIA group. The pain occurred in the same areas in all groups, while the anterior region was less painful in nerve blockade group. The LIA group received a higher number of doses of $100 \mathrm{mg}$ of tramadol intravenously ( $10 \%$ vs. $0 \%$, respectively; $\mathrm{p}<0.008)$, although there was no significant difference in doses of NSAIDs, $50 \mathrm{mg}$ of intravenous of $150 \mathrm{mg}$ of oral tramadol, and fixed pharmaceutical orally administered mixture of $75 \mathrm{mg}$ of dexketoprofen and $25 \mathrm{mg}$ of tramadol.

(a)

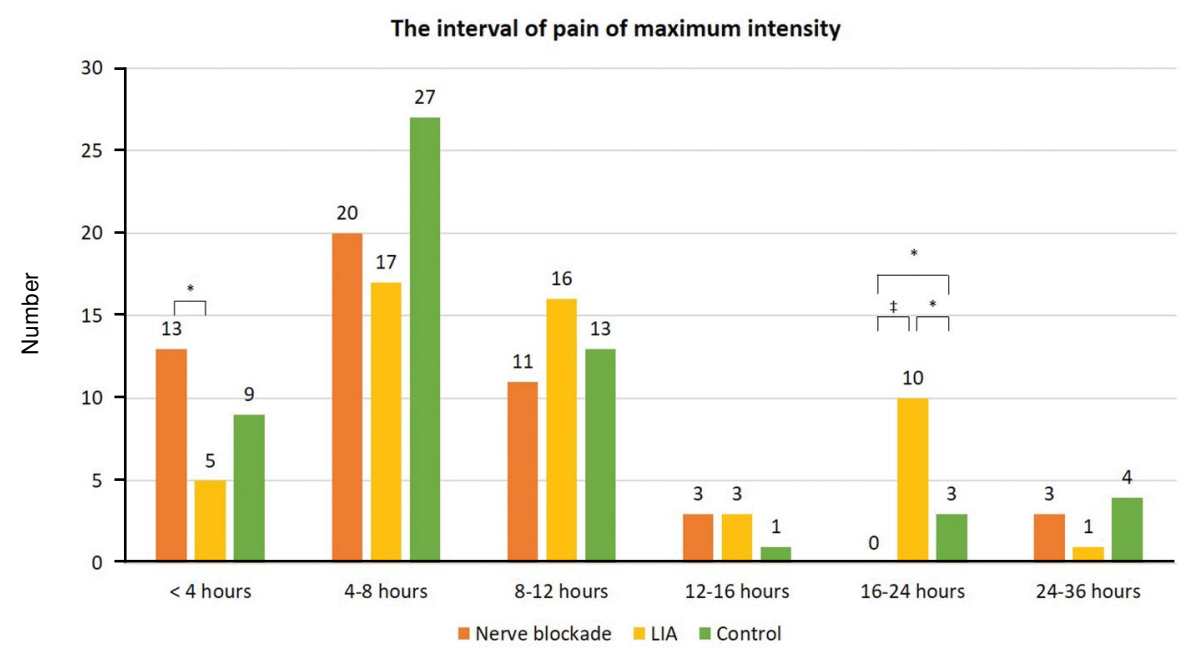

(b)

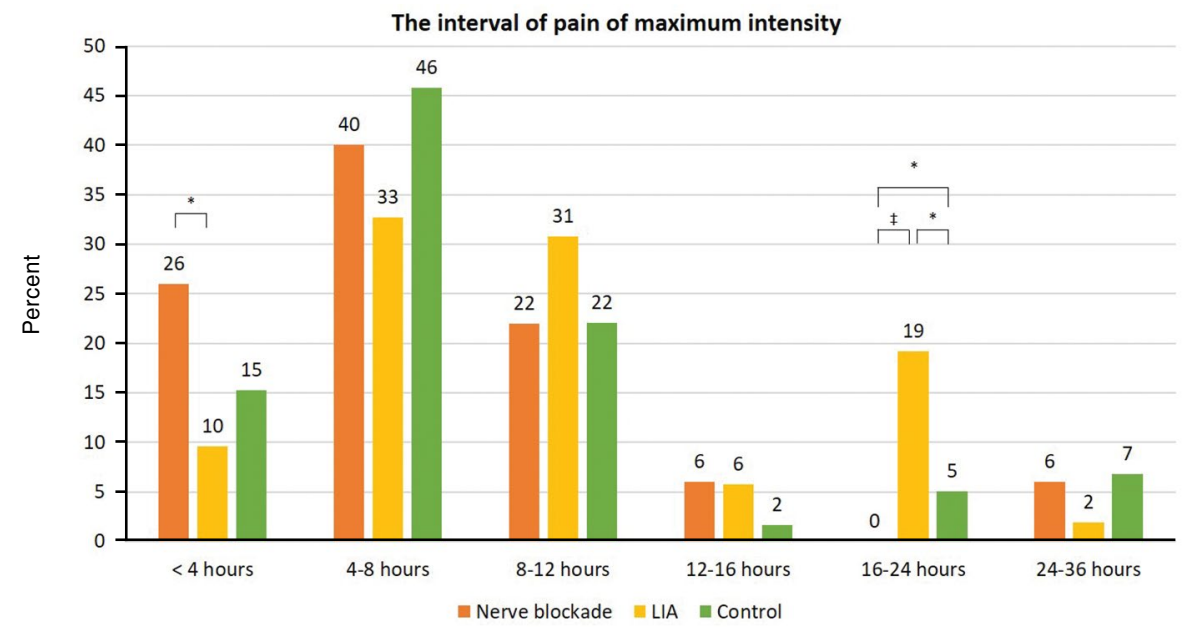

FIGURE 3. The maximum of pain intensity at postoperative $36 \mathrm{~h}$. (a) in numbers of patients; (b) in percentage of group. 
Postoperatively, at 24 to $36 \mathrm{~h}$, tolerable pain was observed in $19 \%, 3 \%$, and $10 \%$ of nerve blockade, LIA, and control groups, respectively. A high intensity of pain was reported only in the control group

(a)

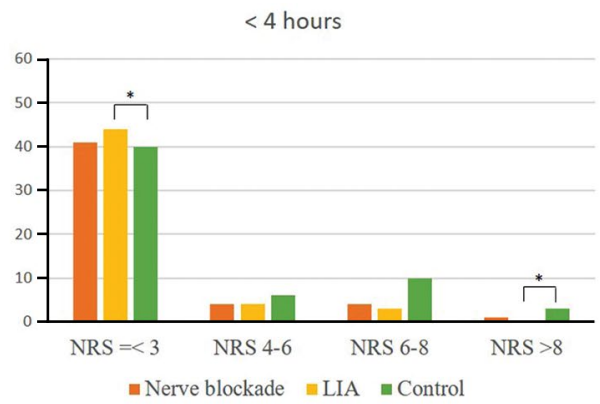

8-12 hours

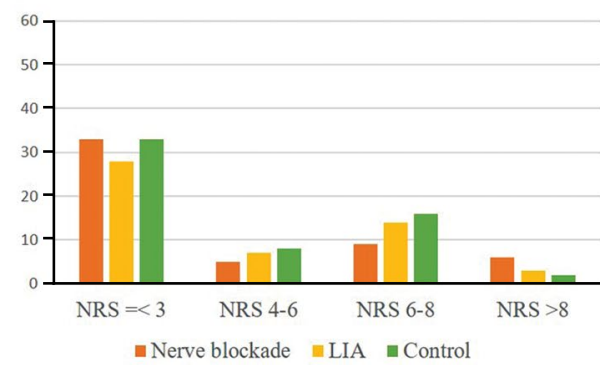

(b)

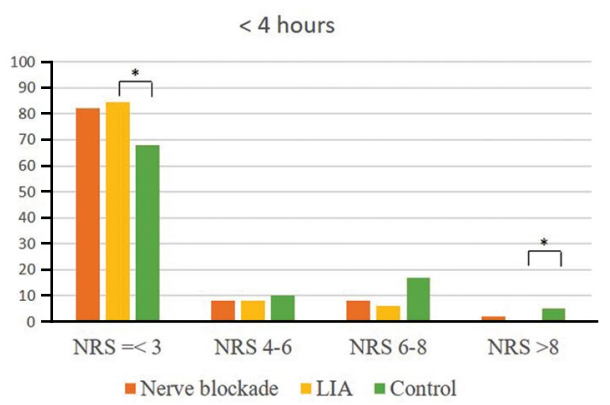

8-12 hours

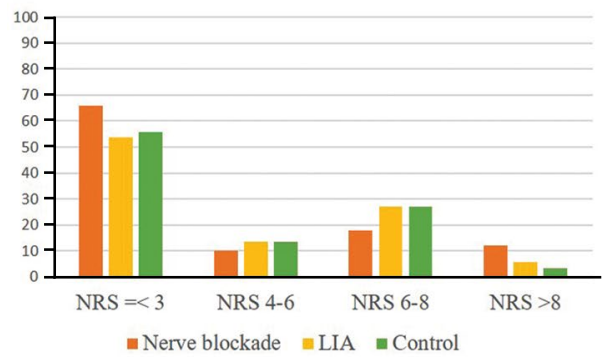

(8\%). The patients of LIA group received a higher number of doses of $50 \mathrm{mg}$ of tramadol intravenously ( $4 \%$ vs. $0 \%$, respectively; $\mathrm{p}<0.01$ ), although there was no significant difference in doses of NSAIDs, $100 \mathrm{mg}$
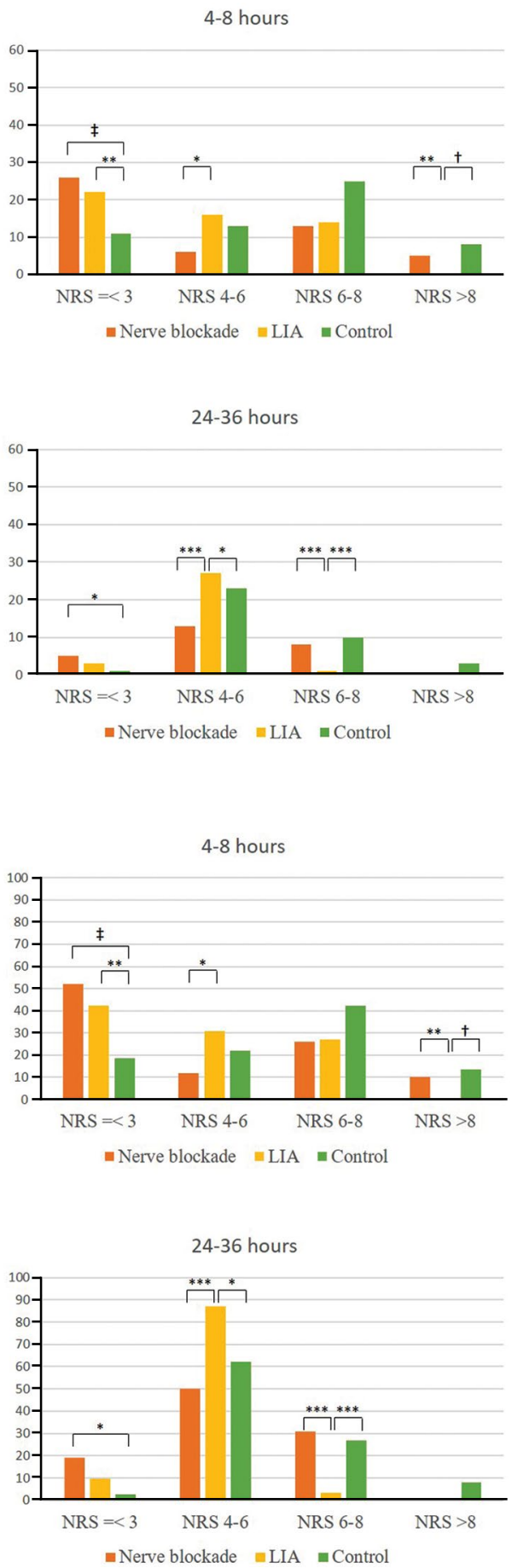

FIGURE 4. The intensity of pain: tolerable (NRS $\leq 3$ ), moderate (NRS 4-6), high (NRS 6-8) and worst possible (NRS >8). a) in numbers of patients; b) in percentage of group.

LIA: Local infiltration analgesia; NRS: Numerical Rating Scale; ${ }^{*} p<0.05 ;{ }^{* \star} p<0.01 ;{ }^{* \star \star} p<0.005 ; \dagger p<0.001 ; \ddagger p<0.0001$. 


\begin{tabular}{|c|c|c|c|c|c|c|}
\hline \multicolumn{7}{|c|}{$\begin{array}{c}\text { TABLE II } \\
\text { Serum hemoglobin levels }\end{array}$} \\
\hline & \multicolumn{2}{|c|}{ Nerve blockade group } & \multicolumn{2}{|c|}{ LIA group } & \multicolumn{2}{|c|}{ Control group } \\
\hline & Median & IQR & Median & IQR & Median & IQR \\
\hline \multicolumn{7}{|l|}{ Hemoglobin (g/L) } \\
\hline Preoperative & 142 & $130-153$ & 143 & $135-151$ & 140 & $133-151$ \\
\hline POD 1 & 123 & $115-135$ & 124 & $114-132$ & 124 & $114-132$ \\
\hline POD 3 & 120 & $112-126$ & 120 & $114-130$ & 120 & $111-126$ \\
\hline \multicolumn{7}{|c|}{ Decrease in hemoglobin (\%) } \\
\hline POD 1 & 13 & $8-17$ & 14 & $9-16$ & 12 & $8-16$ \\
\hline POD 3 & 15 & $12-19$ & 14 & $10-19$ & 15 & $10-20$ \\
\hline POD 1-POD 3 & 3 & $0-8$ & $1^{a, b}$ & $-3-4^{a, b}$ & 3 & $1-9$ \\
\hline
\end{tabular}

of intravenous of $150 \mathrm{mg}$ oral tramadol, and fixed pharmaceutical orally administered mixture of $75 \mathrm{mg}$ of dexketoprofen and $25 \mathrm{mg}$ of tramadol. For power analysis, the common language effect size for pain in each referred interval was communicated, falling in each group between 0.507 and 0.674 . The value between 0.5 and 0.7 is usually interpreted as the intermediate effect. ${ }^{[16]}$

The decline in hemoglobin levels between the first and third postoperative days was significantly lower in the LIA group (Table II). Transfusion of packed red cells was needed in one patient in the nerve blockade, and in one patient in the control group, but none of the patients in the LIA group. The common language effect size for decrease of hemoglobin levels between the first and third postoperative days fell between 0.533 and 0.649 . No adverse effect was observed among the groups.

\section{DISCUSSION}

Peripheral nerve blockades have a prominent role in modern anesthesia. The knee joint is innervated by the femoral-, sciatic-, and obturator nerve. In addition, the femoral nerve is the most important and easiest nerve to find with ultrasound; however, anesthesia of other nerve fibers may theoretically improve analgesia without significantly increasing costs and time.

In the present study, we performed the blockades of these nerves in supine position mostly under spinal anesthesia after surgery. Ultrasound guidance allows us to achieve successful field blocks, which remarkably lessens the risk of persistent neural impairment. A further advantage can be that field block underneath the iliac fascia allows the spread of the local anesthetic to the lateral femoral cutaneous nerve. These surgeries were done with an inflated tourniquet to minimize the intraoperative blood loss. The tourniquet, itself, can be a source of postoperative pain causing pressure damage of nerves.

Local infiltration of the joint during surgery with local anesthetics has been a known modality for decades, revived in 2008 by Kerr and Kohan. ${ }^{[17]}$ Its theoretical background lies in the assumption that pain is best alleviated at the site of its development, in the present case in the knee joint itself. The advantage is that the motor functions remain intact. Nearly all lateral femoral cutaneous nerve is blocked by LIA. In our study, tranexamic acid was also added to the solution to reduce blood loss besides systematic administration. In the present study, in the field of pain relief between the LIA and the block group, neither was superior to the other. Adding tranexamic acid to the LIA solution may decrease the risk of bleeding.

In the current study, the pain was maximal between 4 and $8 \mathrm{~h}$ postoperatively, when the effect of the spinal anesthetic drugs disappeared. During this critical period, significantly a higher number of patients reported low pain (NRS $\leq 3$ ) in the LIA and block groups than in the control group. None of the patients complained of high-intensity pain $($ NRS $>8)$ in the LIA group, which was a significant difference from the block and control groups. At 24 and $36 \mathrm{~h}$ postoperatively, the difference narrowed, which correlates with our pharmacological knowledge, as the effect of these drugs subsides over this time. The only notable being for the rescue analgesics, that lower pain values were seen in the 
LIA group, which were achieved besides higher doses of tramadol.

In our hospital, on the first postoperative day, physical therapists help the patients to stand up and walk using elbow crutches or walking frame, which is a pivotal issue for rapid recovery. The second-day task was to walk short distances (10 to $30 \mathrm{~m}$ ) and, on the third postoperative day, stair climbing was instructed. If any of these tasks could not be carried out, due to muscular weakness, it was considered to be decreased muscular function. Based on the responses of our physical therapists, it was clear that the physiotherapy started on the first postoperative day was not hampered by the peripheral nerve block.

A couple of studies employed local anesthetic administered to only femoral nerve, ${ }^{[3-10]}$ only in two studies provided blockade each of the three the nerves supplied the joint of the knee. ${ }^{[11,12]} \mathrm{A}$ systematic review reported less overall pain scores, opioid consumption, and more extended overall range on motion in the first $72 \mathrm{~h}$ after TKA, when femoral nerve block was combined with sciatic or obturator nerve block or with both. ${ }^{[18]}$ In one of these studies, the femoral and sciatic nerve were blocked with or without obturator nerve blockade. Interestingly, obturator nerve block was seen also in $60 \%$ in the other group due to possible 3-in-1 block as described by Winnie et al. ${ }^{[19]}$ Complete analgesia was achieved in $87.5 \%$ vs. $77.8 \%$ of patients, respectively and the total morphine consumption was higher in the patients without obturator nerve blockade. ${ }^{[1]}$

A recently conducted study compared the continuous intraarticular administration of ropivacaine with the combined continuous femoral, sciatic, and single-shot obturator nerve block. ${ }^{[12]} \mathrm{A}$ slightly better pain relief, but more frequent motor blockade, and even persisting quadriceps weakness were observed in the perineural catheter group.

There is a limited number of studies comparing analgetic properties of LIA and femoral nerve blockade (single dose or continuous) in the literature. Some of them have proved that LIA is superior, ${ }^{[20-22]}$ while some others have suggested that although its analgesic effect is similar to the blockade, LIA is easier to perform and is not associated with motor block. ${ }^{[2,3-5,7,14-29]}$ Based on our results, we can speculate that, in the immediate postoperative period, both LIA and extended block significantly reduce pain and, therefore, their use is definitely recommended. Between the LIA and the block group, neither was superior to the other in our study. However, due to the time spent and the lower costs, we have reasons to assume that the use of LIA in our hospital may be preferable.

Intraoperative blood loss requiring transfusion is negligible in primary TKA owing to the effect of tourniquet. In our hospital, in the absence of contraindications, we routinely administer tranexamic acid for TKA and hip arthroplasties. In our study, in the LIA group, the patients received $500 \mathrm{mg}$ of tranexamic acid in addition to the analgesic drugs into the knee joint. The decline in hemoglobin levels was significantly lower in the LIA group than the control and block groups. The study showed no significant side effects of additional tranexamic acid to LIA solution. These findings suggest that a topical anesthetic may actually reduce the risk of bleeding. Nevertheless, further studies are needed to support our promising results.

The main limitation of the present study is the lack of data regarding the development of chronic pain syndrome. Initially, we planned to investigate this aspect; however, the second wave of novel coronavirus 2019 (COVID-19) pandemic did not allow us to examine this subject.

In conclusion, our study demonstrates that LIA technique offers a fast and safe treatment option for pain relief. Significant advantages were also achieved in blood loss. However, in terms of pain relief, the extended nerve block can be considered equivalent to LIA. No clinically relevant muscle weakness was observed among the groups according to the field block applications. At the discretion of the physician, this is also an appropriate method for postoperative analgesia.

\section{Declaration of conflicting interests}

The authors declared no conflicts of interest with respect to the authorship and/or publication of this article.

\section{Funding}

The authors received no financial support for the research and/or authorship of this article.

\section{REFERENCES}

1. Levent A, Köse Ö, Linke P, Gehrke T, Çıtak M. Does tourniquet use decrease blood loss following primary total knee arthroplasty in Jehovah's Witness patients? Jt Dis Relat Surg 2020;31:419-25.

2. Andersen LØ, Kehlet H. Analgesic efficacy of local infiltration analgesia in hip and knee arthroplasty: A systematic review. Br J Anaesth 2014;113:360-74.

3. Toftdahl K, Nikolajsen L, Haraldsted V, Madsen F, Tønnesen EK, Søballe K. Comparison of peri- and intraarticular analgesia with femoral nerve block after total knee arthroplasty: A randomized clinical trial. Acta Orthop 2007;78:172-9. 
4. Yun XD, Yin XL, Jiang J, Teng YJ, Dong HT, An LP, et al. Local infiltration analgesia versus femoral nerve block in total knee arthroplasty: A meta-analysis. Orthop Traumatol Surg Res 2015;101:565-9.

5. Parvataneni HK, Shah VP, Howard H, Cole N, Ranawat AS, Ranawat CS. Controlling pain after total hip and knee arthroplasty using a multimodal protocol with local periarticular injections: A prospective randomized study. J Arthroplasty 2007;22(6 Suppl 2):33-8.

6. Koh IJ, Kang YG, Chang CB, Do SH, Seong SC, Kim TK. Does periarticular injection have additional pain relieving effects during contemporary multimodal pain control protocols for TKA?: A randomised, controlled study. Knee 2012;19:253-9.

7. Li JW, Ma YS, Xiao LK. Postoperative pain management in total knee arthroplasty. Orthop Surg 2019;11:755-61.

8. O'Donnell R, Dolan J. Anaesthesia and analgesia for knee joint arthroplasty. BJA Educ 2018;18:8-15.

9. Frassanito L, Vergari A, Zanghi F, Messina A, Bitondo M, Antonelli M. Post-operative analgesia following total knee arthroplasty: Comparison of low-dose intrathecal morphine and single-shot ultrasound-guided femoral nerve block: A randomized, single blinded, controlled study. Eur Rev Med Pharmacol Sci 2010;14:589-96.

10. Karlsen AP, Wetterslev M, Hansen SE, Hansen MS, Mathiesen O, Dahl JB. Postoperative pain treatment after total knee arthroplasty: A systematic review. PLoS One 2017;12:e0173107.

11. McNamee DA, Parks L, Milligan KR. Post-operative analgesia following total knee replacement: An evaluation of the addition of an obturator nerve block to combined femoral and sciatic nerve block. Acta Anaesthesiol Scand 2002;46:95-9.

12. Lützner J, Gehring R, Beyer F. Slightly better pain relief but more frequently motor blockade with combined nerve block analgesia compared to continuous intraarticular analgesia after total knee arthroplasty. Knee Surg Sports Traumatol Arthrosc 2020;28:1169-76.

13. Abonyi B, Pap K, Gal T, Vasarhelyi G, Udvarhelyi I, Hangody L. A comparison of SanatMetal Sanat Swing and Zimmer NexGen ${ }^{\circledR}$ total knee implants: 10-year postoperative followup results. Jt Dis Relat Surg 2021;32:10-6.

14. Childs JD, Piva SR, Fritz JM. Responsiveness of the numeric pain rating scale in patients with low back pain. Spine (Phila Pa 1976) 2005;30:1331-4.

15. ClinCalc. Kane SP Sample Size Calc ClinCalc https:// clincalc.com/stats/samplesize.aspx Updat July 24, 2019 [Accessed: February 10, 2020]

16. Ruscio J. A probability-based measure of effect size: Robustness to base rates and other factors. Psychol Methods 2008;13:19-30.

17. Kerr DR, Kohan L. Local infiltration analgesia: A technique for the control of acute postoperative pain following knee and hip surgery: A case study of 325 patients. Acta Orthop 2008;79:174-83.

18. Terkawi AS, Mavridis D, Sessler DI, Nunemaker MS, Doais KS, Terkawi RS, et al. Pain management modalities after total knee arthroplasty: A network meta-analysis of 170 randomized controlled trials. Anesthesiology 2017;126:923-37.

19. Winnie AP, Ramamurthy S, Durrani Z. The inguinal paravascular technic of lumbar plexus anesthesia: The "3-in-1 block". Anesth Analg 1973;52:989-96.

20. Ashraf A, Raut VV, Canty SJ, McLauchlan GJ. Pain control after primary total knee replacement. A prospective randomised controlled trial of local infiltration versus single shot femoral nerve block. Knee 2013;20:324-7.

21. Broome CB, Burnikel B. Novel strategies to improve early outcomes following total knee arthroplasty: A case control study of intra articular injection versus femoral nerve block. Int Orthop 2014;38:2087-9.

22. Antoni M, Jenny JY, Noll E. Postoperative pain control by intra-articular local anesthesia versus femoral nerve block following total knee arthroplasty: Impact on discharge. Orthop Traumatol Surg Res 2014;100:313-6.

23. Chaumeron A, Audy D, Drolet P, Lavigne M, Vendittoli PA. Periarticular injection in knee arthroplasty improves quadriceps function. Clin Orthop Relat Res 2013;471:2284-95.

24. Spangehl MJ, Clarke HD, Hentz JG, Misra L, Blocher JL, Seamans DP. The Chitranjan Ranawat Award: Periarticular injections and femoral \& sciatic blocks provide similar pain relief after TKA: A randomized clinical trial. Clin Orthop Relat Res 2015;473:45-53.

25. $\mathrm{Hu} \mathrm{B}$, Lin $\mathrm{T}$, Yan SG, Tong SL, Yu JH, Xu JJ, et al. Local infiltration analgesia versus regional blockade for postoperative analgesia in total knee arthroplasty: A metaanalysis of randomized controlled trials. Pain Physician 2016;19:205-14.

26. Ng FY, Ng JK, Chiu KY, Yan CH, Chan CW. Multimodal periarticular injection vs continuous femoral nerve block after total knee arthroplasty: A prospective, crossover, randomized clinical trial. J Arthroplasty 2012;27:1234-8.

27. Affas F, Nygårds EB, Stiller CO, Wretenberg P, Olofsson C. Pain control after total knee arthroplasty: A randomized trial comparing local infiltration anesthesia and continuous femoral block. Acta Orthop 2011;82:441-7.

28. Moghtadaei M, Farahini H, Faiz SH, Mokarami F, Safari S. Pain management for total knee arthroplasty: Singleinjection femoral nerve block versus local infiltration analgesia. Iran Red Crescent Med J 2014;16:e13247.

29. Uesugi K, Kitano N, Kikuchi T, Sekiguchi M, Konno S. Comparison of peripheral nerve block with periarticular injection analgesia after total knee arthroplasty: A randomized, controlled study. Knee 2014;21:848-52. 